\title{
Revascularization of the Freely Grafted Extensor Digitorum Longus Muscle in the Rat
}

\author{
F.M. HANSEN-SMITH, ${ }^{1}$ B.M. CARLSON, AND K.L. IRWIN \\ Department of Anatomy, University of Michigan, Ann Arbor, Michigan 48109
}

\begin{abstract}
The process of revascularization of free grafts of the extensor digitorum longus muscle in rats has been studied by gross, histological and electron microscopic methods. During the first day after transplantation the muscle is entirely avascular, and it consists of a thin peripheral zone of surviving muscle fibers and a large central area of ischemic muscle. The original blood vessels of the graft undergo a sequence of intrinsic and cell-mediated destruction. Scattered sinusoidal vessels begin to grow into the graft starting on the second day, and ingrowing blood vessels progressively invade the deeper tissues of the graft. Most new vessels form in the connective tissues, but some vessels, especially larger ones, grow into persisting basal laminae from preexisting vessels and, occasionally, even into basal laminae from degenerated muscle fibers and nerves. The differentiation of new arterioles and venules in free muscle grafts is described. By the end of the first week, the entire graft is revascularized, and ultimately a fairly normal relationship between new capillaries and regenerating muscle fibers is established. In mature grafts, however, irregularities are sometimes found in the organization of smooth muscle cells associated with larger vessels.
\end{abstract}

In a free muscle graft, a skeletal muscle is placed into a host site without any direct connection between the vascular beds of the graft and host. The outer few layers of muscle fibers in the graft survive, apparently through the diffusion of oxygen and nutrients, but the remainder of the muscle fibers in the interior of the graft fall into a state of ischemic necrosis (Hansen-Smith and Carlson, '79). The spatiotemporal pattern of the phagocytic removal of ischemic muscle fibers and their replacement by muscle fibers regenerating from myoblasts and myotubes depends upon the revascularization of the graft.

The degeneration of the microcirculatory vessels in ischemic or injured skeletal muscle has been described at the light- and electronmicroscopic levels (Clark and Blomfield, '45; Hurley and Edwards, '69; Strock, '69; Dahlbäck, '70; Vracko and Benditt, '72; Mäkitie, '77). Prolonged ischemia leads to the disruption and fragmentation of the endothelial cells, with the basal laminae remaining (Hurley and Edwards, '69; Strock, '69; Vracko and Benditt, '72; Mäkitie, '77). The basal laminae are thought to provide a "scaffold" for the regeneration of muscle fibers and for the replacement of endothelial cells as injured or ischemic muscles become revascularized (Vracko and Benditt, '72). Thus, the original vascular pathways appear to be important during muscle regeneration when the muscle has not been severed from its original blood supply. It is less clear, however, to what extent the original blood vessels contribute in the revascularization of freely grafted muscles, since they have been severed from the parent vessels. Nor has the pattern of revascularization of freely grafted muscles been adequately described histologically or ultrastructurally. Hakelius and Nyström ('75) used histochemical techniques to examine the revascularization of cat leg muscles grafted into the intercostal spaces. They demonstrated that most of the original capillaries degenerated, but the role of these original structures in the process of revascularization could not be ascertained by the techniques used. The results of their study also suggested that the larger vessels may survive (or remain structurally identifi-

'Present address: University of Detroit, Department of Anatomy, 2985 E. Jefferson, Detroit, Michigan 48207.

Send correspondence to Dr. Bruce M. Carlson, Department of Anatomy, University of Michigan, Ann Arbor, Michigan 48109.

Received July 7, '79. Accepted Feb. 21, '80. 
able) and may eventually anastomose with ingrowing vessels from the recipient bed.

In contrast, the entire muscle, including its intrinsic vessels, may be minced before grafting. Even though this trauma severely limits the re-utilization of the original vascular channels, the implanted mass of muscle fragments becomes revascularized by the ingrowth of a network of vessels growing out from the surrounding tissue (Carlson, '70, '72).

In this communication we describe the revascularization of free grafts of the extensor digitorum longus muscle of the rat at the gross, histological, and electron-microscopic levels. The results suggest that many of the observations concerning both the vascular degeneration following ischemia and the revascularization process in non-grafted, but injured or ischemic muscles also hold true for grafted muscles. Many of the original vascular pathways are re-utilized, although the original endothelial cells and many smooth muscle cells are destroyed. New pathways also arise, particularly at the level of the capillaries.

\section{METHODS}

Male Sprague-Dawley rats (175-200 g) from Charles River Farms were used for this study. The extensor digitorum longus (EDL) muscle of one leg was freely grafted, as reported previously (Carlson and Gutmann, '75), with the opposite side serving as a control. The muscle, including its neurovascular bundle, was completely excised and was then grafted back into the original bed. It was sutured to the tendons of origin and insertion, but no vascular or neural connections were made. The animals were anesthetized by ether during the grafting procedure and at the time of removal of the muscles for analysis.

A total of 71 grafted muscles were examined after $1-8,10,15,20,30,60,67$ or 120 days. India ink (Pelikan, C 11/1431A, Günther Wagner) was injected via the abdominal aorta just prior to removal of the muscles. One group of injected muscles was fixed in $10 \%$ formic acid, cleared in methyl salicylate, and used for gross examination. A second group was fixed in Bouin's fixative, stained with hematoxylin and eosin and used for histological examination. A third group was used for electronmicroscopic examination. Sample blocks for electron microscopy were taken from the middle third of the muscle and fixed overnight in $2 \%$ cacodylate-buffered glutaraldehyde $(\mathrm{pH}$ 7.38). The tissues were post-fixed in $1 \%$ caco- dylate-buffered osmium tetroxide, dehydrated in ethanol, and embedded in Spurr resin. Survey sections $(1 \mu \mathrm{m})$ were stained with toluidine blue. Gold or silver sections for electron microscopy were examined with a Hitachi HU11A electron microscope. Non-injected grafts were also examined by electron microscopy.

\section{RESULTS}

\section{Vascular supply of the normal EDL muscle}

The normal EDL muscle contains one major nutrient artery, which enters the muscle about one-third to one-half the way down its proximo-distal axis and courses distad down the muscle as a straight vessel. Numerous lateral branches leave the main artery and give rise to the smaller vessels that run parallel to the individual muscle fibers. Smaller vessels radiate from the site of entry of the main nutrient vessel. Accompanying the branches of the motor nerves are smaller vessels that supply much of the proximal onethird of the muscle. Vessels entering through the tendons supply small areas at either end of the muscle.

\section{Observations on gross specimens of grafts with injected vessels}

One day after grafting, the muscle was unstained; by two days, there were only isolated areas of injected superficial vessels. At three days, scattered networks of distended larger vessels just beneath the surface of the graft were injected, and groups of injected capillaries were lined up in roughly parallel arrays along the long axis of the muscle. The superficial regions of four-day grafts contained more injected vessels of larger diameter, and there was also greater penetration of capillaries toward the avascular center of the graft.

After the sixth day, injected vessels filled the entire graft. In areas with many muscle fibers, the smaller vessels were oriented in parallel arrays, but in areas of loose connective tissue, there was much more irregular lateral branching. By day 8 , distended large (probably original) vessels could no longer be distinguished. A major difference between the vascular pattern of mature grafts (up to 68 days) and the normal EDL muscle was the absence of a prominent single nutrient vessel running down the distal half of the muscle. Instead, the muscle was commonly subdivided into several poorly defined vascular territories, probably the result of multiple vessels growing into the grafts. 


\section{Histological observations}

During the first day, greatly dilated veins and arteries packed with blood cells were found in the center of the graft. There was essentially no ink staining of the graft, yet the outer half of the graft contained a scattering of polymorphonuclear leukocytes. By 2 days, areas of injected capillaries were scattered over the periphery of the graft. In areas where breakdown of old muscle fibers had occurred and myoblasts were lining up prior to fusing, injected new blood vessels were prominent. Ink was occasionally seen in thrombosed degenerating large vessels, as well. At 3-5 days, there were numerous injected vessels in areas of early regeneration (myotube formation) and around the periphery of the graft (Fig. 1). Some of the larger original vessels contained ink particles. In almost all cases, the area where original muscle fibers were being broken down by macrophages lay closer to the center than the furthest incursion of blood vessels.
By 6 days, the original muscle fibers were gone, and injected vessels were seen throughout the graft. Areas of regenerating muscle fibers were well vascularized, whereas areas of dense connective tissue were poorly vascularized.

In a mature graft (67 days) most capillaries ran parallel to the muscle fibers, and the relations of capillaries to muscle fibers looked normal. There were, however, more irregular vessels, with diameters larger than capillaries, going through these grafts than there are in normal muscles.

\section{Electron-microscopic observations}

Almost all of the original capillaries degenerated within the first day after grafting. Only fragments of endothelial cells were found within the basal laminae of the capillaries, and often the interior of the basal lamina tube was devoid of cellular material. The nuclei of the endothelial cells became pyknotic and disappeared. Degenerating capillaries rarely had

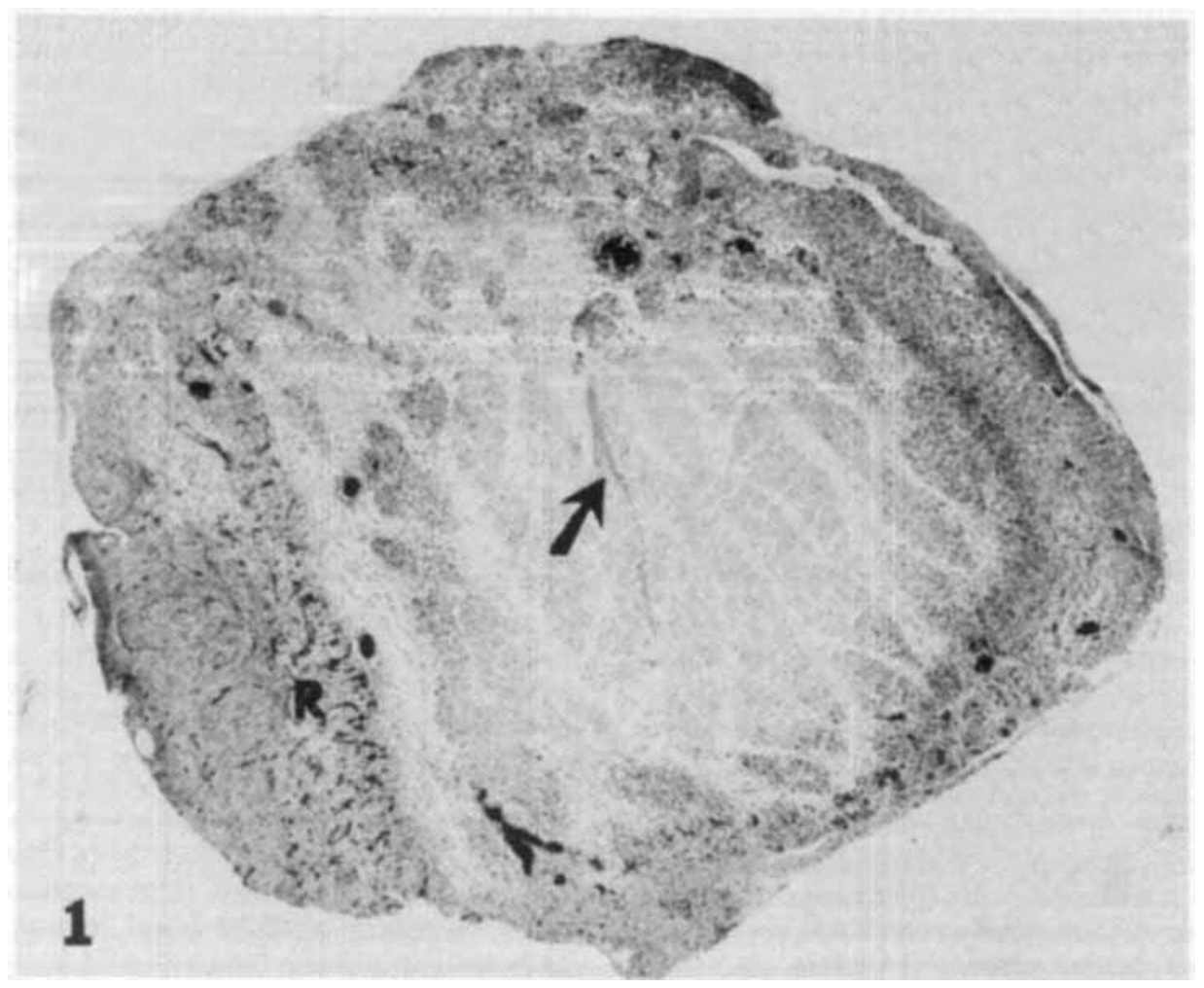

Fig. 1. Histological section from a 4-day graft shows ink-injected vessels in the regenerating zone (R). The central zone, including a large vessel (arrow), is uninjected. 
pericytes associated with them, but intact pericytes were occasionally observed. A few of the capillaries within the zone of surviving muscle fibers remained structurally intact, but they lacked pinocytotic vesicles. The endothelial cells and some smooth muscle cells of the larger blood vessels fragmented and subsequently disappeared, except for some cellular debris (Fig. 2).

The first blood vessels to grow into the graft were "sinusoidal" thin-walled endothelial tubes with large lumens (Fig. 3). These tubes initially formed a branching network around the surviving muscle fibers. As they grew inward, the endothelial tubes were often partially enveloped in the loose folds of basal laminae from degenerated muscle fibers. Endothelial cells were flattened and elongated, with moderately euchromatic nuclei. Occasional cells protruded into the lumen, however. These cells usually had highly euchromatic nuclei or were undergoing mitosis. Cells constituting the endothelial tube were joined together by junctional complexes. Pinocytotic vesicles were sometimes present at the inner and outer surfaces, but they were not numerous. These endothelial tubes were lined by a single layer of basal lamina.

Capillary sprouting and the differentiation of muscular regions of the blood vessel began within a day after the initial ingrowth of simple endothelial tubes among the muscle fibers of the graft. At this time, the lumens of the endothelial tubes became irregular, with flaps of cytoplasm protruding toward the lumen (Fig. 4). These were presumed to represent the origin of capillary sprouts or branches from the endothelial tubes. Mitotic cells were observed frequently (Fig. 6). The walls of the earliest-formed capillaries were usually thicker than those of normal capillaries (Fig. 5). The lumens of many of these thick-walled capillaries were nearly occluded by the cytoplasm of the endothelial cells. Such regions were considered to be near the tip of a capillary sprout. Other thinner-walled capillaries were presumably "older" capillaries, and their nuclei were more heterochromatic than those of the newly formed capillaries. The capillaries contained few pinocytotic vesicles during the early stages of vascularization in the grafts. Capillaries were always surrounded by a layer of closely adherent basal lamina. As with the larger sinusoidal vessels, capillaries sometimes lay in a "trough" created from the basal laminae of surrounding degenerating muscle fibers (Fig. 6). Pericapillary cells formed a semicircular cuff around many of the capillaries observed four or more days after grafting (Fig. 7). Some of these cells were relatively thin and contained few organelles. However, most of the pericapillary cells were very large and contained extensive rough endoplasmic reticulum; their nuclei were large and euchromatic. Pericapillary cells were often incompletely covered by a basal lamina.

Regions of the thin-walled endothelial tubes subsequently differentiated into arterioles or venules. The latter were distinguished by the acquisition of a second, usually discontinuous, layer of electron-dense cells which were partially or completely surrounded individually by their own basal lamina (Fig. 8). The cells were elongated and flattened and were initially similar in appearance to inactive fibrocytes. These cells subsequently synthesized myofilaments, and dense bodies characteristic of smooth muscle were formed.

The endothelial cells and associated cells of arterioles differed from the corresponding cells that differentiated into venules. In transverse sections, the developing arterioles were composed of several large endothelial cells that bulged into the lumen (Fig. 9). A second layer of cells, separated from the endothelium by the endothelial basal lamina, partially or completely encircled the endothelial cells. These cells also became surrounded individually by their own basal laminae, except where they were connected by junctional complexes. These fibrocyte-like cells were thicker and had larger and more euchromatic nuclei than the perivascular cells associated with the venules. These cells subsequently differentiated into smooth muscle (Fig. 10). Myoendothelial junctions were present in both the arterioles and venules prior to the actual differentiation of the smooth muscle cells (Fig. 9).

The initial endothelial vessels growing into the graft did not appear to utilize any preexisting pathways. However, once the vascular supply became established at the periphery, some of the endothelial cells grew into preexisting tubes formed from collapsed basal laminae or from the structural remains of larger vessels. Capillaries were found within loose tubes of basal lamina ranging in size from that of a capillary (Fig. 5) to that of a larger vessel. They were also occasionally found sharing a common basal lamina with regenerating muscle fibers (Fig. 11). In one specimen a large vein was found within a degenerated nerve. During the early stages of revascularization, the skeletons of larger ves- 

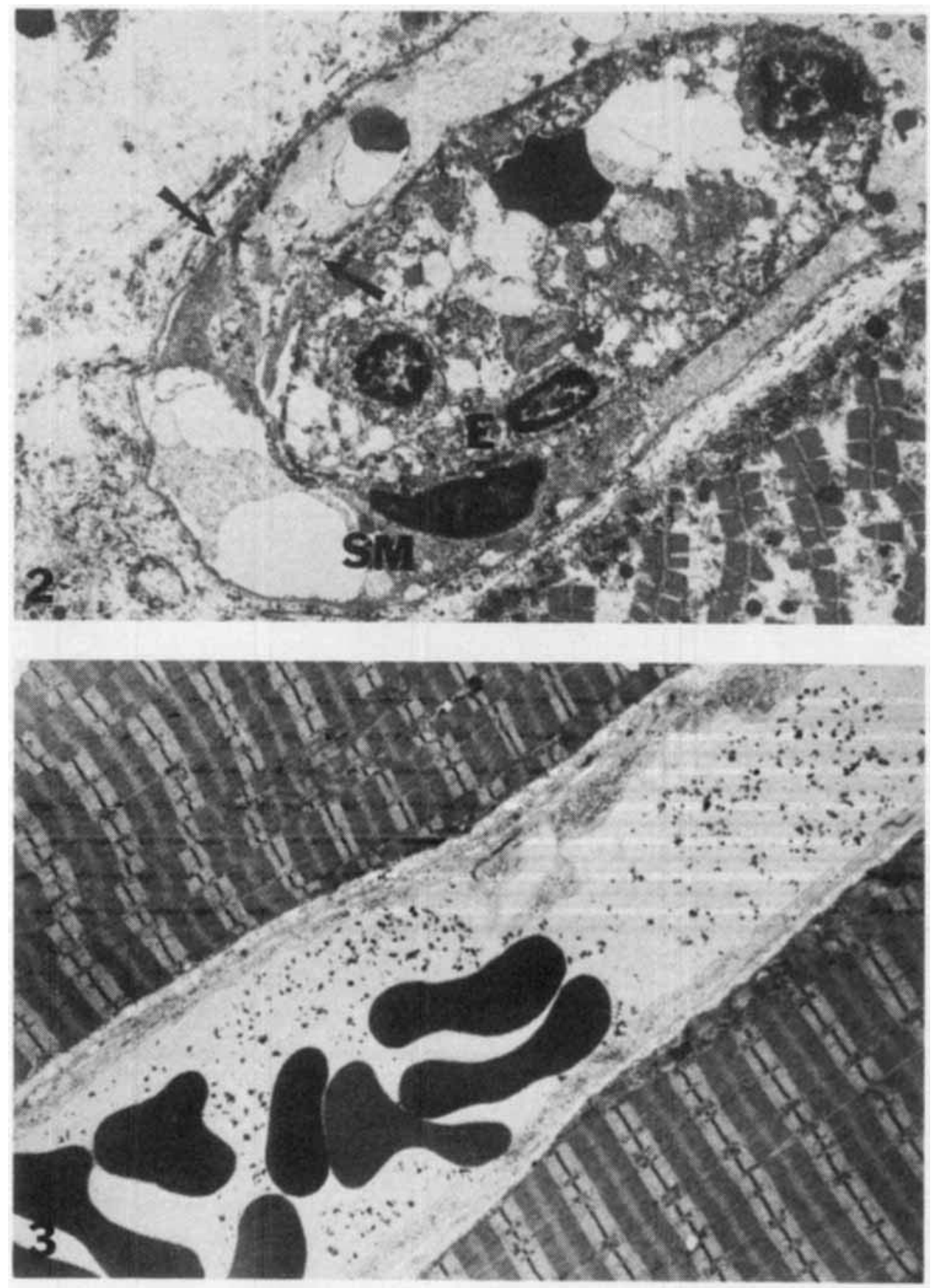

Fig. 2. An arteriole from a 1-day graft shows degeneration of both the endothelium (E) and the smooth muscle cells (SM). Basal laminae from the original endothelium and from the smooth muscle cells persist (arrows). An ischemic skeletal muscle fiber is seen at the lower right. $\times 4600$.

Fig. 3. A thin-walled endothelial tube from a 3-day graft is found between two surviving muscle fibers. The lumen of the vessel contains erythrocytes and particles of India ink. $\times 4500$. 


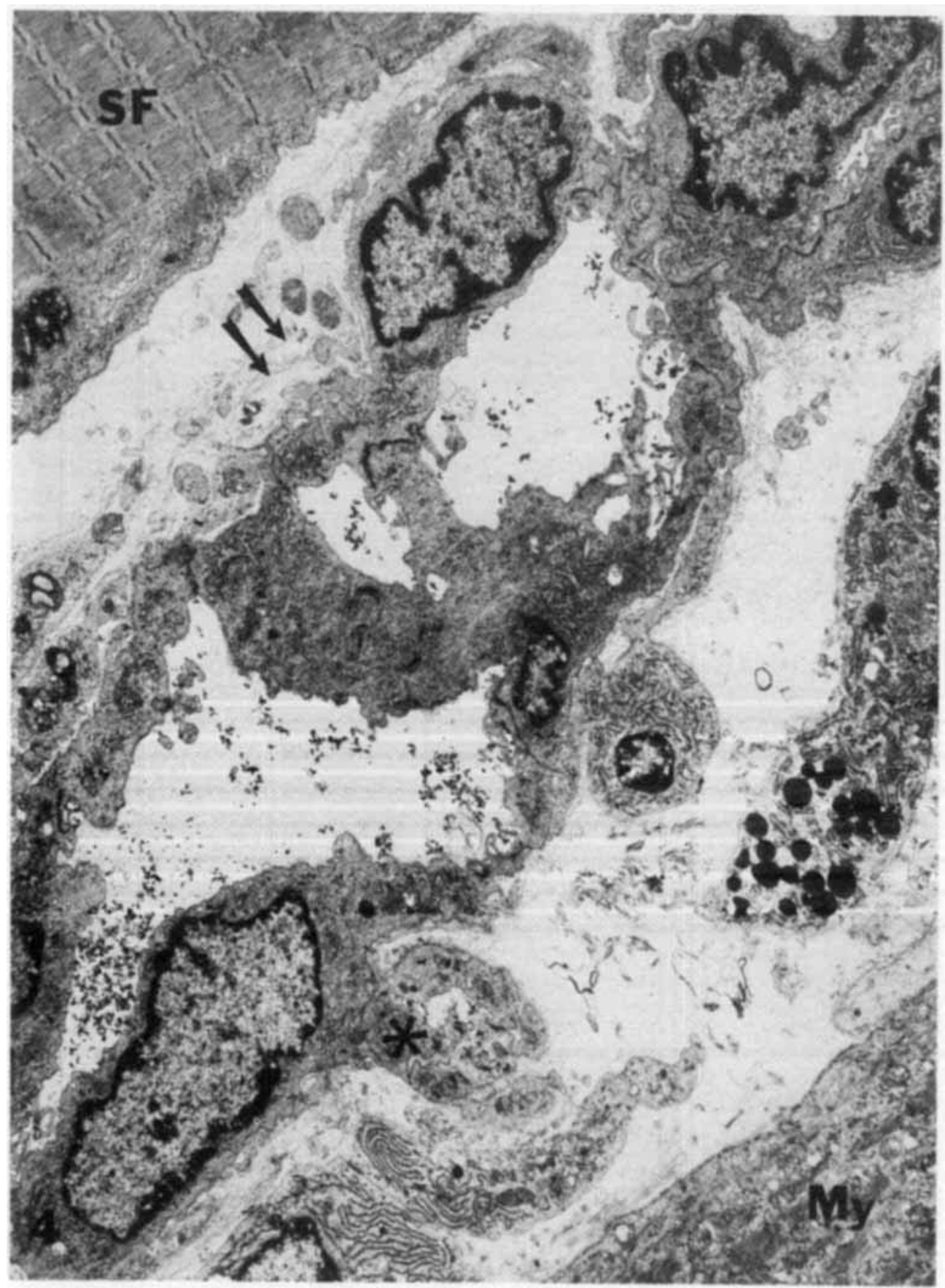

Fig. 4. An endothelial tube containing India ink is found between a surviving fiber (SF) and a myotube (My), in a 5-day graft. The irregularity of the endothelial cells suggests the formation of branches. A capillary sprout containing ink is evident (*). Loose basal laminae are found along the sides of the endothelial tube (arrows). $x$ 8000 

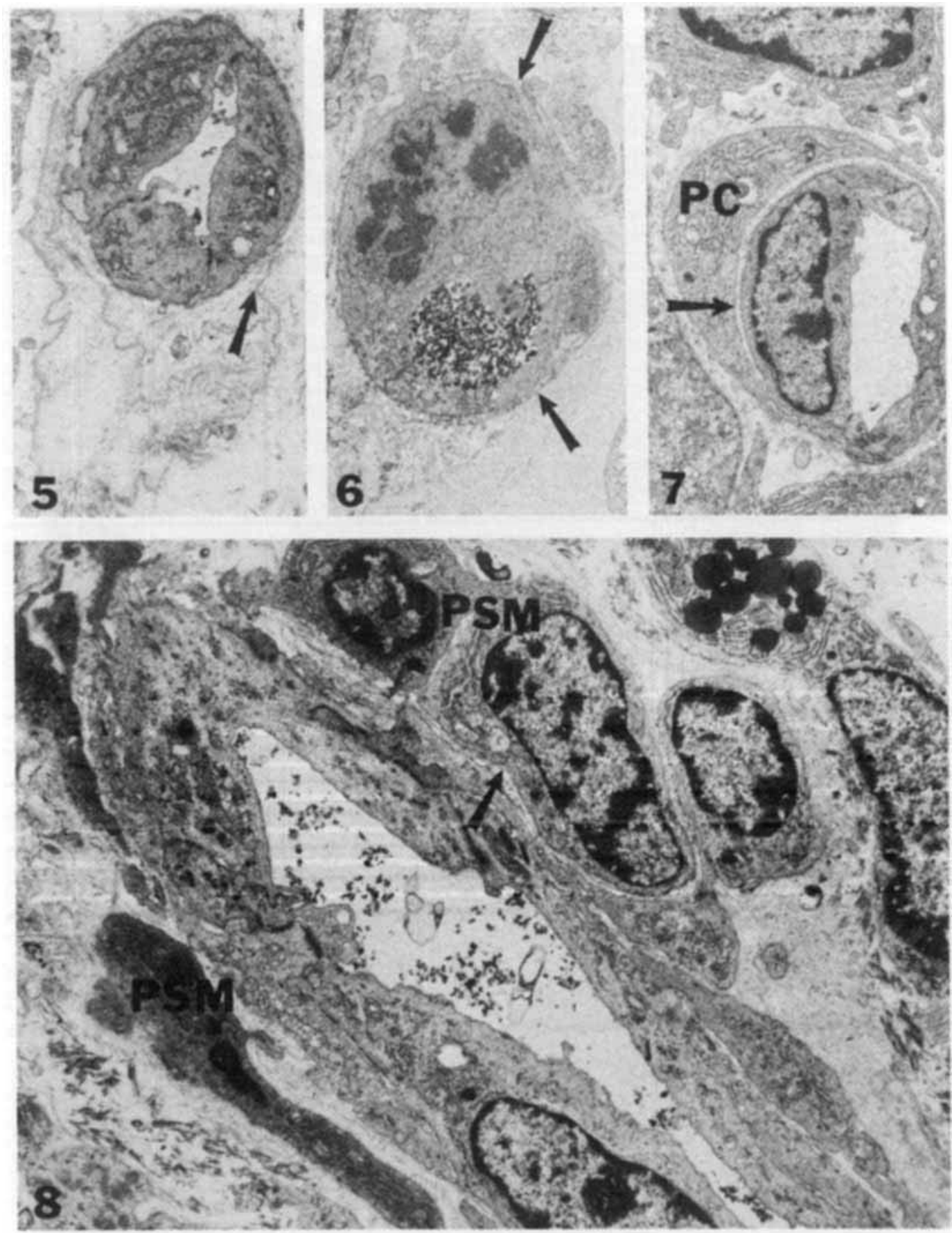

Fig. 5. A capillary from a 6-day graft has grown into a preexisting basal lamina (arrow). The capillary lumen contains a few ink particles. $\times 5600$.

Fig. 6. An endothelial cell in a 4-day graft is undergoing mitosis. The lumen of the capillary is filled with ink. Basal laminae from adjacent degenerating muscle fibers are closely associated with the capillary, forming a guiding "trough" (arrows). $\times 4600$.

Fig. 7. A pericapillary cell (PC) is associated with a capillary found in a 6-day graft. The basal lamina surrounding the pericapillary cell is incomplete (arrows). $\times 5000$

Fig. 8. A developing venule in a 6-day graft has undifferentiated presumptive smooth muscle cells (PSM) associated with the endothelium. The presumptive smooth muscle cells are partially covered by a basail lamina (arrow). The lumen of the venule contains ink. $\times 6000$ 

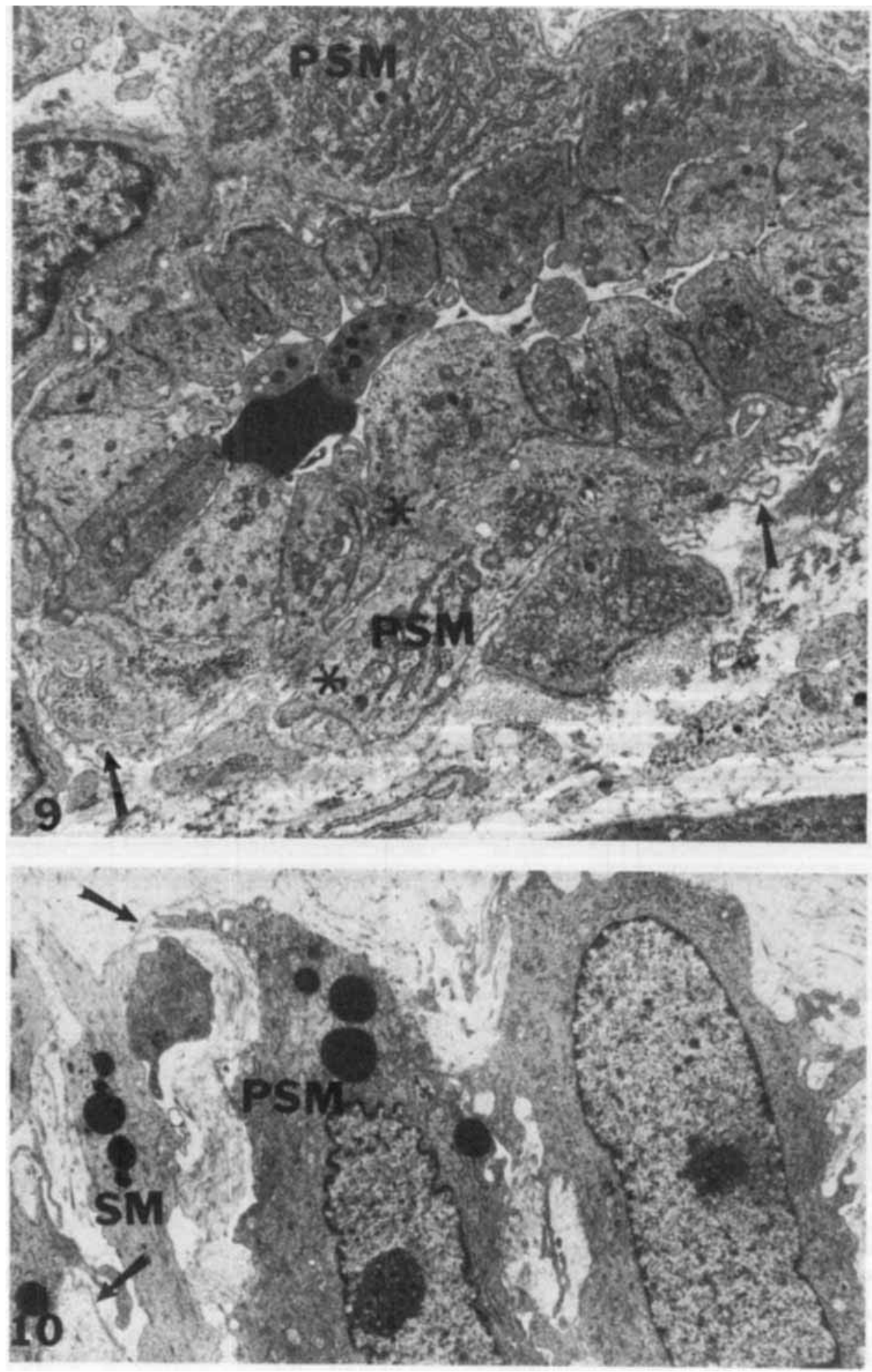


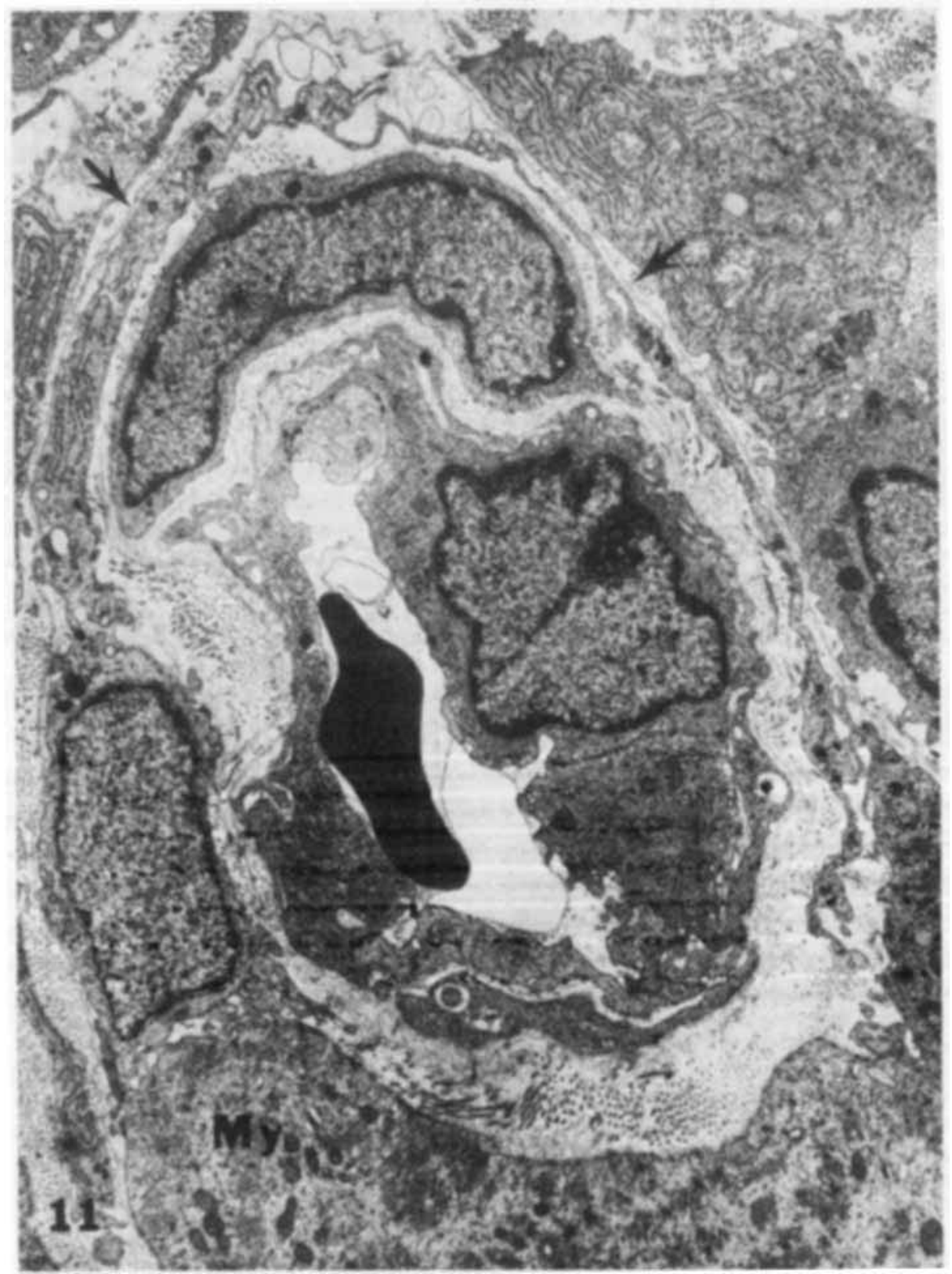

Fig. 11. A blood vessel is found within the confines of the original basal lamina (arrows) surrounding a regenerating myotube $(\mathbf{M y})$ in a 7-day graft. The blood vessel also has its own basal lamina. $\times 9300$.

Fig. 9. Presumptive smooth muscle cells (PSM) are associated with the endothelium of a developing arteriole in a 6-day graft. Myo-endothelial junctions are present $\left(^{*}\right)$. Loose, original basal lamina envelopes the vessel (arrows). Ink is found in a vessel's lumen. $\times 6400$.

Fig. 10. A differentiating smooth muscle cell (SM) and a presumptive smooth muscle cell (PSM) are found within the original basal laminae (arrows) of a degenerated blood vessel in a 5-day graft. Dense bodies and myofilaments are found in the differentiating smooth muscle cell but not in the presumptive smooth muscle cells. $\times 6000$. 
sels served as conduits to shunt blood toward the ischemic interior of the graft, even though the cellular organization of the vessels was disrupted. Ink particles were found within these tubes prior to the reestablishment of a continuous endothelial lining. Endothelial cells migrating within the remaining tubes of basal lamina contained large amounts of free and bound ribosomes (Fig. 12); their appearance was quite similar to that of the presumptive myoblasts found within the basal laminae of muscle.

As noted earlier, the smooth muscle cells in the original vessels were disrupted after grafting. Many of the smooth muscle cells of the media degenerated to a homogeneous mass in which swollen mitochondria, filamentous bodies and autolytic vacuoles were present (see Fig. 12). The smooth muscle cell nuclei became pyknotic and many underwent karyolysis. Erythrocytes migrated through the media and into the degenerating smooth muscle cells. A few of the smooth muscle cells remained viable. Although some degenerative changes occurred within these cells, the cell membranes remained intact. Basal laminae underlying the degenerated endothelium and around the surviving and the degenerated smooth muscle cells were preserved. The elastic laminae also persisted.

After continuity with the peripheral circulation was established, neutrophils and macrophages invaded the media of the larger vessels, as well as the surrounding tissue (Fig. 13). The extent of destruction of degenerated smooth muscle cells was not entirely clear, because it was almost impossible to distinguish between phagocytosis of smooth and of skeletal muscle in more advanced stages.

Smooth muscle cells became more numerous in the media once the basal lamina of an old vessel was reendothelialized. Some of these cells appeared to be well-differentiated at an early stage, and they may have been surviving smooth muscle cells. Other cells within the media were completely undifferentiated and contained many bound and unbound ribosomes, but lacked myofilaments and dense bodies (Figs. 8, 9). Another type of cell was intermediate, having much RNA, but also myofilaments and dense bodies (Fig. 10). Although the differentiating smooth muscle cells were found within the loose confines of the original smooth muscle basal laminae, the cells themselves did not always have a complete, closely adherent basal lamina (Figs. 8-10). As observed in maturing and mature grafts, the final smooth muscle coat in these re-utilized blood vessels was sometimes abnormal. For example, in some grafts, the smooth muscle coat had proliferated adjacent to the endothelium inside the elastic layer, whereas smooth muscle was not normally found inside the elastic layer in controls (Fig. 14). An arteriole found in a mature graft was surrounded by a smooth muscle layer aligned along the original basal lamina, but there was no structural relationship between the two layers (Fig. 15).

The original basal laminae surrounding the re-utilized blood vessels were still present in mature grafts. Cellular debris sometimes persisted inside these basal laminae (Fig. 14). We made no attempt to quantify precisely the extent to which re-utilization of vascular tubes occurred. However, on the basis of the presence of a loose, redundant basal lamina as an indication of re-utilization, a rough estimate of the ratio of "new" to pre-utilized pathways would be 10:1 for capillaries, and 2:1 for arterioles and venules. The few larger muscular arteries that were found all appeared to have regenerated within the skeleton of the original vessels. Empty tubes of basal lamina were also found in the mature grafts.

The overall architecture of the vascular tree was established within 7-10 days after grafting. At this time, the graft consisted of fascicles of thin regenerating fibers. Each fascicle contained only 1 or 2 capillaries. As the fibers enlarged, the capillary supply expanded. By 30 days after grafting, a normal pattern of capillarity (i.e., 3-4 capillaries surrounding each fiber) was observed. During this period of capillary proliferation, some of the capillaries, presumably the most recent sprouts, still had thick walls. By 30 days after grafting, the structures of the majority of the capillaries (Fig. 16), as well as many of the vessels of the microcirculation, were similar to those found in normal muscle. However, in the larger vessels numerous irregularities were found in the organization of the smooth muscle cells, relative to the endothelium (Figs. 14, 15).

\section{DISCUSSION}

As a result of this investigation, it is now possible to reconstruct an overall sequence of revascularization of free muscle grafts in the rat (Fig. 17). The first postoperative day is characterized by massive degeneration of virtually all the vascular elements. The graft becomes revascularized by sinusoidal vessels which soon begin to differentiate into recog- 

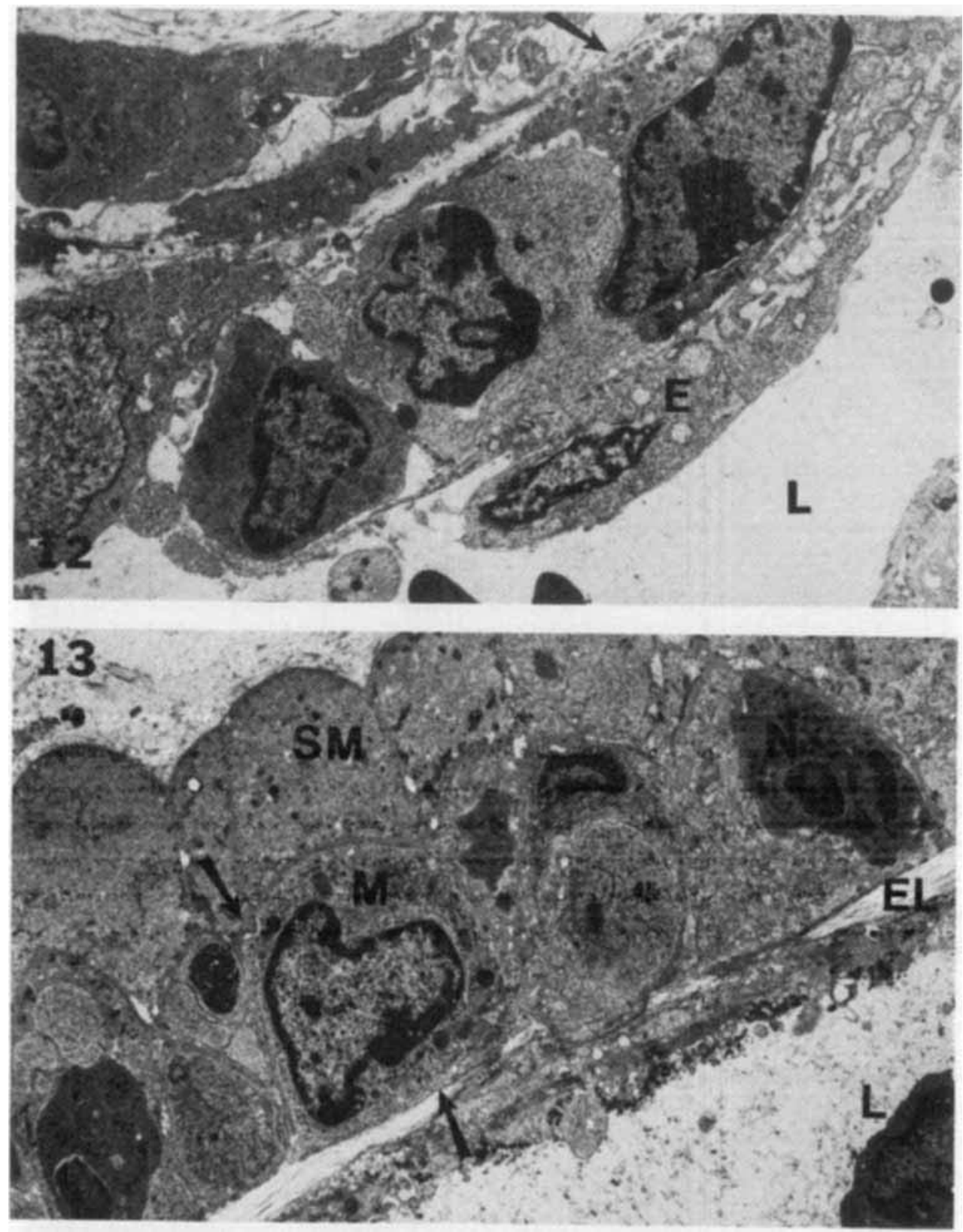

Fig. 12. A blood vessel is regenerating within a basal lamina tube (arrow) in a 5 -day graft. An endothelial cell (E) is part of a discontinuous lining of the lumen (L). Although there are no ink particles present in the figure, an adjacent region of the same vessel contained ink. The other cells associated with the blood vessel cannot be positively identified. $\times 5000$.

Fig. 13. A degenerated arteriole near the center of a 5-day graft contains India ink in its lumen (L). The vessel thus serves as a non-viable conduit. The endothelial cells and the smooth muscle cells (SM) of the media have degenerated, but the elastic lamina (EL) and the basal laminae (arrows) persist. Neutrophils (N) and monocytes (M) have invaded the media. $\times 6000$. 


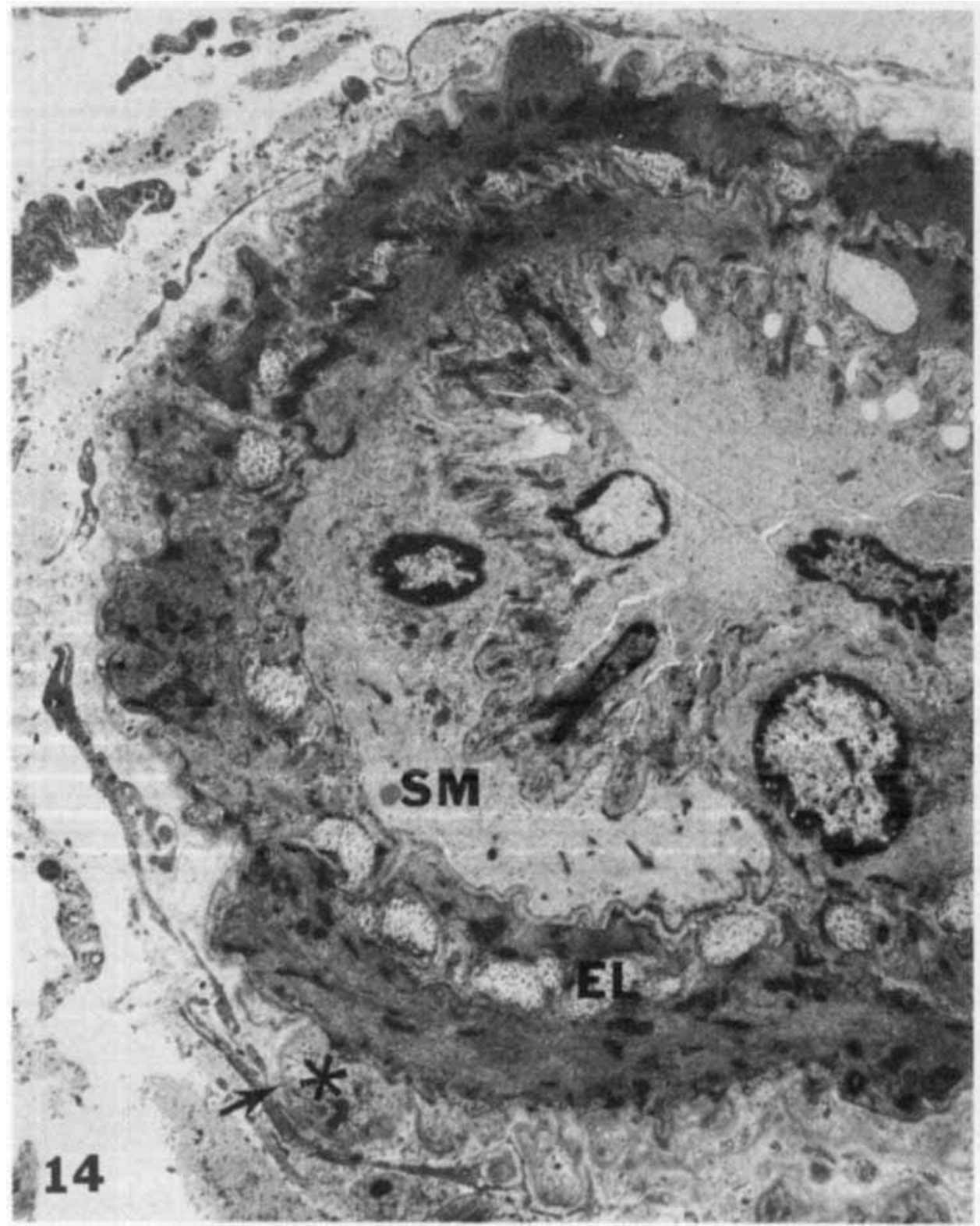

Fig. 14. An arteriole found in a 39-day graft has smooth muscle cells (SM) on the luminal side of the elastic lamina (EL). The basal lamina (arrow) and some debris $\left(^{*}\right)$ from the original vessel persist. $\times 5600$. 


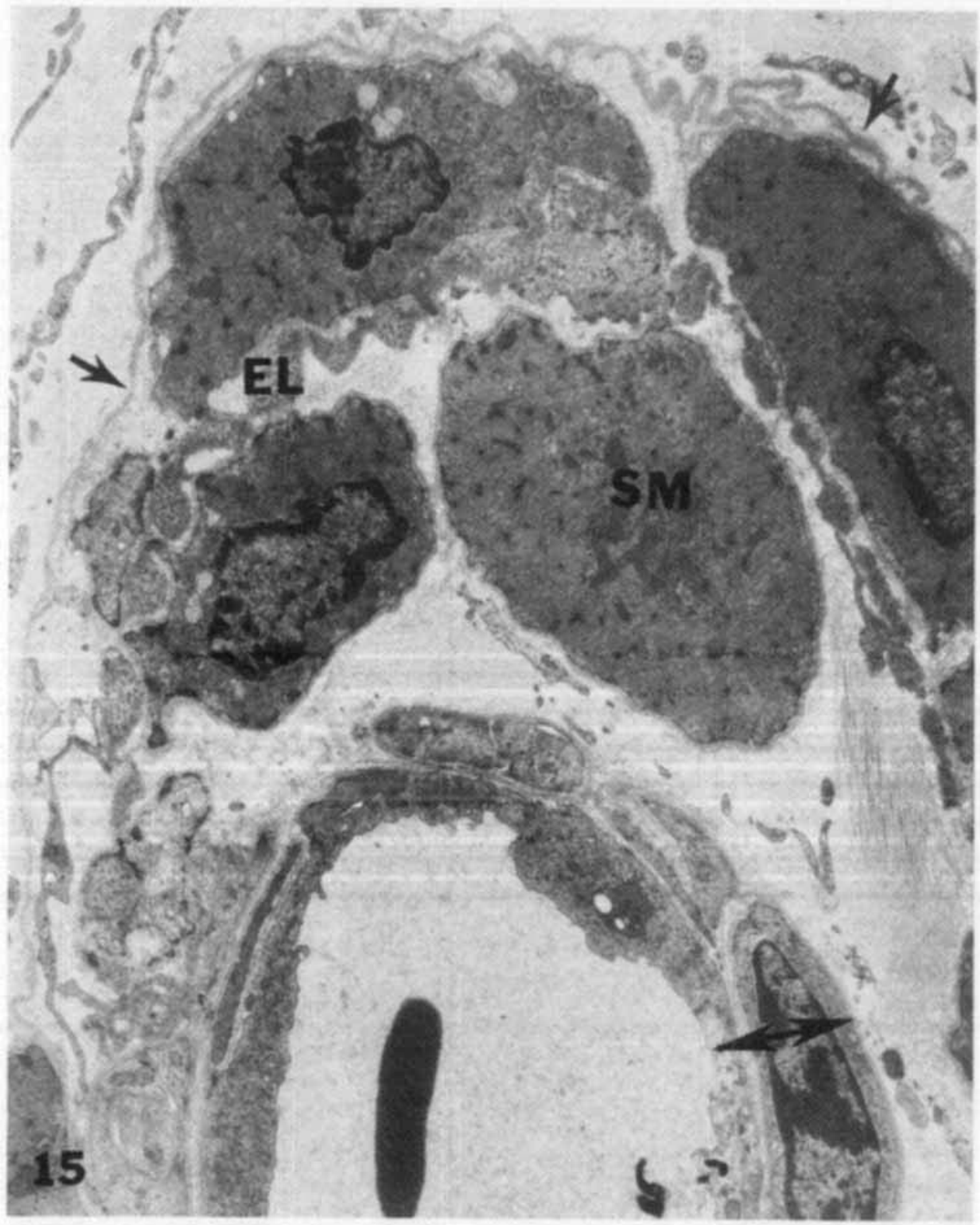

Fig. 15. A blood vessel in a 60-day graft has grown inside of the basal lamina (arrows) and elastic lamina (EL) remaining from the original blood vessels in the muscle. The wall of the regenerated blood vessel (double arrow) is composed of a layer of endothelium and a layer of smooth muscle. Other smooth muscle cells (SM) are found within the original basal lamina but are not specifically associated with the regenerated blood vessel. $\times 8700$. 


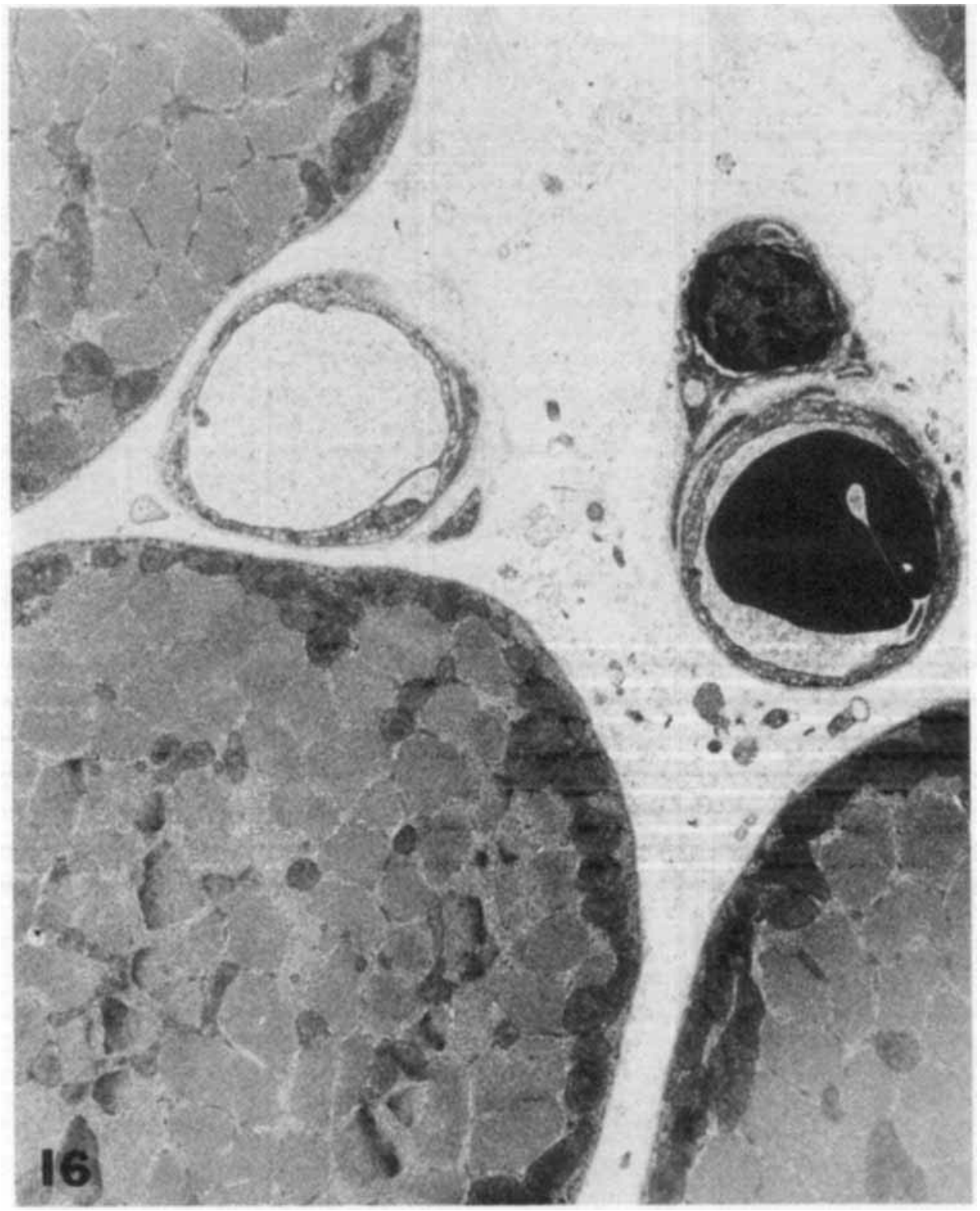

Fig. 16. Capillaries and muscle fibers found in this 60-day graft are normal in appearance. $\times 8600$. 

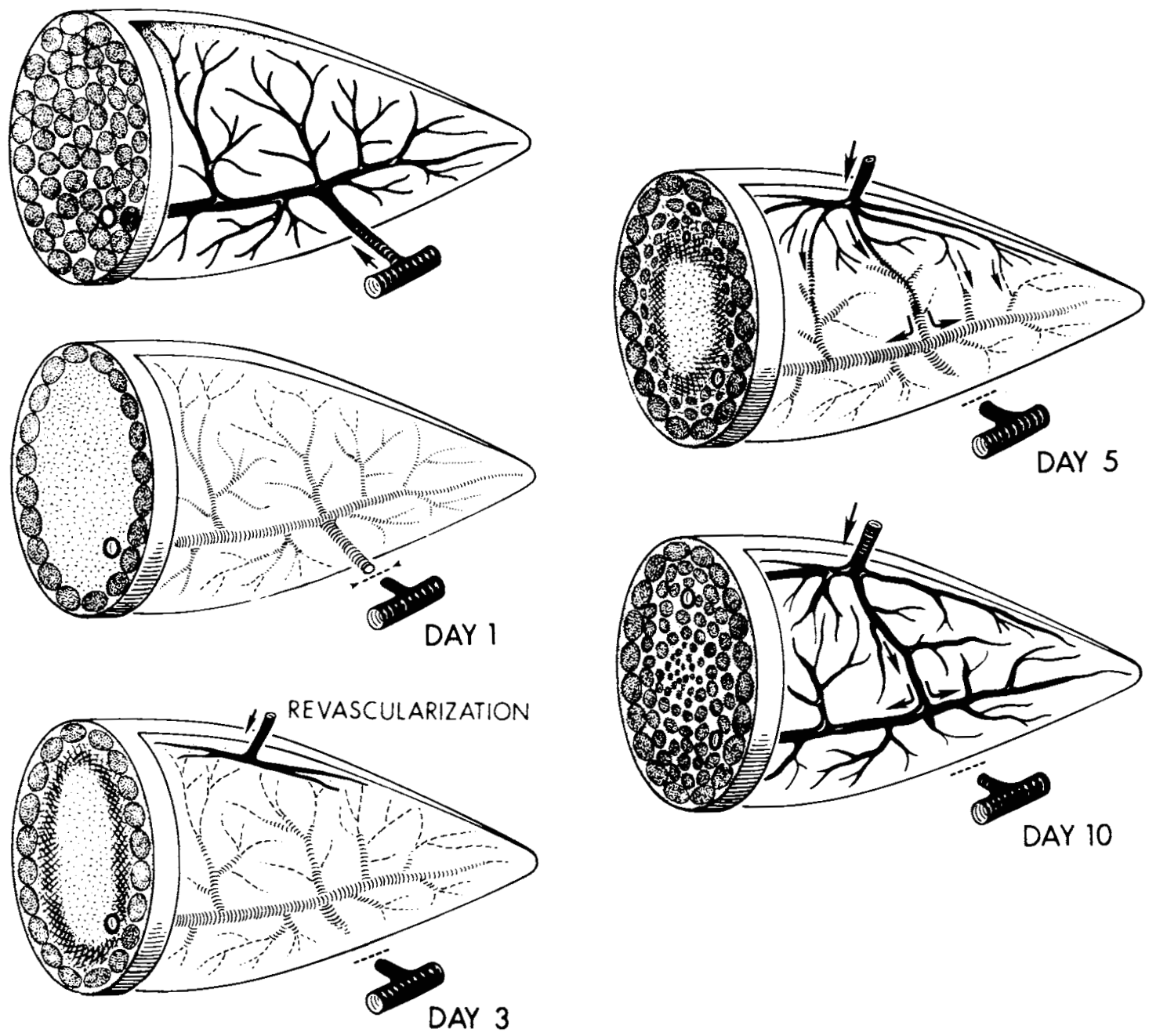

Fig. 17. Summary diagrams illustrating the revascularization of free muscle grafts. Day 1: The larger vessels in the graft are severely ischemic and most capillaries have degenerated. The cut face of the muscle shows surviving muscle fibers (dark circles) and ischemic muscle fibers (central stippling). Day 3: New blood vessels begin to grow into the graft. Corresponding with this, a zone of muscle degeneration and regeneration (cross-hatching in cut surface) is established. Day 5: Ingrowing blood vessels occupy a greater portion of the graft. Some new vessels are growing down the lumens of old, degenerating ones, and some larger original vessels are re-utilized as vascular channels. The flow of blood is indicated by arrows. Day 10: The graft is completely revascularized, with an amalgamation of old and new blood vessels. Within the peripheral zone of surviving muscle fibers, the central part of the graft is filled with thin regenerating muscle fibers. 
nizable capillaries, arterioles or venules. Vessels of larger caliber not infrequently utilize the basal laminae of old vascular channels, muscle fibers, or even nerves, as supporting elements or as substrata for ingrowth. This study has confirmed the supposition (Carlson and Gutmann, '75) that the centripetal progression of fragmentation of ischemic muscle fibers followed by the regeneration of new muscle is a function dependent upon the pattern of revascularization. Thus, despite the lack of mechanical damage to the vasculature of a free muscle graft, its revascularization follows a course very similar to that which occurs in a regenerating minced muscle (Carlson, '70, '72). By the end of the first week, regenerating blood vessels have penetrated to the center of the graft, and ultimately a nearly normal relationship is established between capillaries and the new muscle fibers.

At the cellular level, both muscle fibers and blood vessels in the graft undergo an initial intrinsic destruction. However, phagocytic removal of the cellular debris from the original muscle fibers is rapid and complete. Cellular debris is never found within the basal lamina of a mature fiber, nor is interstitial debris present (Hansen-Smith and Carlson, '79). In contrast, phagocytosis of the cellular debris of blood vessels is incomplete, since debris is still found between the original basal laminae and regenerated blood vessels in mature grafts. This is surprising in view of the fact that circulating macrophages should encounter the cellular debris of the vasculature prior to that of the tissues.

The long-term fate of original basal laminae of blood vessels is different from that of muscle fibers. Most of the loosely folded original basal laminae around the regenerating muscle fibers disappear by the end of the second week after grafting (Hansen-Smith and Carlson, 79). In contrast, loose original basal laminae surrounding blood vessels persist even in the long-term grafts. The tendency of redundant layers of basal laminae to accumulate around capillaries under certain pathological conditions has been documented (Vracko and Benditt, '70; Silver et al., '77; Mäkitie, '77; Jerusalem et al., '74). It has been demonstrated that vascular basal lamina differs immunohistochemically (Midgley and Pierce, '63) and structurally (Huang, '78) from several other kinds of basal lamina.

Growth of capillaries into preexisting tubes of basal lamina was observed in the present study, but the importance of basal laminae as "scaffolding" (Vracko and Benditt, '70, '72) during the revascularization of grafts is not clear. There is no evidence that the earliest sinusoidal vessels are guided by preexisting basal laminae. Only a small proportion of the capillaries found during the early stages of regeneration are surrounded by outer, loose basal laminae that are presumed to have persisted from the blood vessels in the original muscle. The remaining capillaries are surrounded by a single, closely adherent layer of basal lamina that cannot be distinguished as new or old. It is impossible to determine with certainty whether these latter capillaries have grown independently of the original basal laminae or whether some have regrown into preexisting basal laminae. The need for synthesis of an additional basal lamina outside the endothelium may be eliminated if the size of the original persisting tubes of basal lamina is such that the tubes are completely distended by endothelium growing into them. In regenerating muscle, for example, new basal lamina is only deposited at sites where the original basal lamina does not contact the myotubes (Hansen-Smith and Carlson, '79).

It has previously been held that endothelial cells and muscle cells have some means of recognizing their own kind of basal lamina (Vracko and Benditt, '72). However, capillaries in muscle grafts are occasionally found sharing a loose basal lamina with an adjacent myotube. Both the capillaries and the myotubes have also each acquired a second, closely adherent basal lamina. Large blood vessels may also be found, rarely, within the sheaths of degenerating nerve bundles. The dual use of an original basal lamina by two different structures was a relatively uncommon finding in the present study, but it is significant because it suggests that the utilization of basal laminae for structural support may involve less discrimination than had been postulated previously. The suggestion has also been made that only the inside of the tube of basal lamina is recognized by endothelial cells (Vracko and Benditt, '72). However, endothelial tubes are often found closely aligned outside the basal laminae of muscle fibers, usually partially housed in "troughs" created by the collapse of the basal laminae of the fibers. This suggests that capillary growth into the graft may be supported and presumably, guided, by whatever basal laminae are available.

Some of the larger preexisting vascular channels are re-utilized as the grafted EDL becomes revascularized. Initially, these chan- 
nels simply serve as non-viable conduits, since the original endothelium of both the capillaries and the larger vessels has previously degenerated, leaving only cellular debris and the surrounding basal laminae. Hakelius and Nyström ('75) noted that anastomoses occurred between the larger vessels of autografted cat muscles and those of the recipient bed, but they did not comment on the viability of the original vessels. Our observations of the re-utilization of the original vessels as nonviable conduits concur with observations in vivo on the mechanism of revascularization of grafted skin (Zarem et al., '67) and subcutaneous tissue (Williams, '59). Survival and subsequent sprouting of the original vessels within some types of tissue grafts has also been reported as a significant mechanism in revascularization (Gloor and Ludwig, '73; Greenblatt et al., '71; Ausprunk et al., '75; Stevens, '75; Williams, '53; Záhoř and Povýšil, '79). No comparable response by the original blood vessels was observed in our study, possibly because of the large size of the muscle. Only a small number of capillaries remained intact at the periphery of the muscle grafts. Although it could not be determined whether these eventually became incorporated into the vascular network of the graft, these few surviving blood vessels probably did not play a significant role in revascularization. In contrast, the non-viable conduit vessels ultimately became reendothelialized and were incorporated as viable units in the vascular network. The re-utilized vessels may contribute significantly to the success of the graft by shunting macrophages and nutrients into the center of the graft. The shunts could accelerate phagocytic removal of degenerated fibers and, possibly, further the survival of some of the satellite cells in the center of the graft.

To our knowledge there is no information concerning the role of preexisting vascular smooth muscle in the revascularization of tissue grafts. Much of the smooth muscle within both the microcirculatory vessels and the larger vessels degenerates after grafting. However, there was evidence that some of the smooth muscle cells may survive. A few cells within the deteriorating vessels could be clearly identified as smooth muscle. Other viable cells within the vascular wall may have been difficult to recognize because of dedifferentiation (modulation?) (Fritz et al., '70). It is unclear whether, or to what extent, any surviving smooth muscle cells contribute to the walls of the re-utilized blood vessels. The or- ganizational irregularities found in re-utilized arterioles of mature grafts suggest that some smooth muscle cells may persist and proliferate in their original location, despite its spatial separation from the endothelium. An alternative explanation for these abnormal blood vessels is that the original smooth muscle cells may degenerate, but other smooth muscle cells or their progenitors may be attracted to the original smooth muscle basal laminae. In these re-utilized blood vessels, another population of smooth muscle cells, presumably new cells, becomes associated with the endothelial lining in a normal relationship.

The final vascular network in the grafts includes arterioles, venules, and larger muscular vessels that have followed preexisting channels, as well as those that have grown independently of preexisting channels. The latter vessels differentiate normally. Their smooth muscle cells differentiate from fibroblast-like perivascular cells. The appearance of smooth muscle cells in these developing vessels is similar to that observed in blood vessels developing in other tissues (Cliff, '67; Frist and Stemerman, '75) and in tissue culture (Fritz et al., '70).

In summary, this study shows that the endothelial cells and many smooth muscle cells of the original blood vessels are destroyed after a muscle is grafted. Revascularization from the surrounding tissues begins on the second day after grafting. Large "sinusoidal" vessels penetrate the periphery of the graft and rapidly differentiate into capillaries, arterioles, and venules. The endothelial cells also invade and may be guided by empty basal laminae from capillaries and other structures. Anastomoses form between the endothelial tubes and the degenerated cytoarchitecture of the larger original vessels. These vessels initially serve as non-viable conduits, but they subsequently become reendothelialized. The overall pattern of the vascular bed is established within 7-10 days after grafting, although the capillary network continues to proliferate as regenerating fibers enlarge in the maturing graft. The vasculature of the mature graft includes elements from both "new" and re-utilized original blood vessels.

\section{ACKNOWLEDGMENTS}

This work was supported by grants from NIH (NS 13116 and NS 14358) and the MDA. 


\section{LITERATURE CITED}

Allbrook, D. (1962) An electron microscopic study of regenerating skeletal muscle. J. Anat. (Lond.), 96:137-152.

Ausprunk, D.H., D.R. Knighton, and J. Folkman (1975) Vascularization of normal and neoplastic tissues to the chick chorioallantois: Role of host and pre-existing graft blood vessels. Am. J. Pathol., 69:597-618.

Carlson, B.M. (1970) The regeneration of entire muscles from minced fragments. In: Regeneration of Striated Muscle and Myogenesis, eds. A. Mauro, S.A. Shafiq, A.T. Milhorat. Excerpta Medica, Amsterdam. pp. 25-37.

Carlson, B.M. (1972) The Regeneration of Minced Muscles. S. Karger, Basel.

Carlson, B.M. and E. Gutmann (1975) Regeneration in free grafts of normal and denervated muscles in the rat. Morphology and histochemistry. Anat. Rec., 183:47-61.

Clark, W.E. LeGros, and L.B. Blomfield (1945) The efficiency of intramuscular anastomoses with observations on the regeneration of devascularized muscle. J. Anat. 79:15-32.

Cliff, W.J. (1967) The aortic tunica media in growing rats studied with the electron microscope. Lab. Invest., 17:599-615.

Dahlbäck, L. (1970) Effects of temporary tourniquet ischemia on striated muscle fibers and motor end plates. Scand. J. Plast. Reconstr. Surg. Suppl., 7:14-32.

Frist, F, and M.B. Stemerman (1975) Arterial growth and development. In: Vascular Neuroeffector Mechanisms, Second International Symposium, Odense, Karger, Basel (1976). Eds. J.A. Bevan, G. Burnstock, B. Johansson, R.A. Maxwell, O.A. Nedergaard.

Fritz, G., J. Jarmolych, and A.S. Dabud (1970) Association of RNA synthesis and apparent dedifferentiation of aortic smooth muscle cells in vitro. Exp. Mol. Pathol., 12:354-362.

Gloor, M., and G. Ludwig (1973) Revascularization of free full thickness skin autografts. Arch. Derm. Forsch., 246:211-221.

Greenblatt, M., J. Kaufman, and C. Kommineni (1971) Functioning heart homografts in hamsters. Transplantation, 11:50-55.

Hakelius, L, and B. Nyström (1975) Blood vessels and connective tissue in autotransplanted free muscle grafts of the cat. Scand. J. Plastic Reconstr. Surg., 9:87-91.
Hansen-Smith, F.M., and B.M. Carlson (1979) Cellular responses to free grafting of the extensor digitorum longus muscle of the rat. J. Neuro. Sci., 41:149-173.

Huang, T.W. (1978) Composite epithelial and endothelial basal laminae in human lungs. Am. J. Pathol., 93:681-692.

Hurley, J.V., and B. Edwards (1969) Acute inflammation: A combined light- and electron-microscope study of the vascular response to incisional and crushing injury of skeletal muscle in the rat. J. Pathol., 98:41-52.

Jerusalem, F., M. Rakusa, and A.G. Engel (1974) Morphometric analysis of skeletal muscle capillary ultrastructure in inflammatory myopathies. J. Neuro. Sci., 23:391-402.

Mäkitie, J. (1977) Skeletal muscle capillaries in intermittent claudication. Arch. Path. Lab. Med., 101:500-503.

Midgley, A.R., and G.B. Pierce (1963) Immunohistochemical analysis of basement membranes of the mouse. Am. J. Pathol., 43:929-943.

Silver, M.D., VF. Huckell, and M. Lorber (1977) Basement membranes of small cardiac vessels in patients with diabetes and myxoedema: Preliminary observations. $\mathrm{Pa}$ thology, 9:213-220.

Stevens, S.M. (1975) The restoration of the vasculature of skin autografts in the rabbit. Pathology, 7:79-90.

Strock, P.W. (1969) Microvascular changes in acutely ischemic rat muscle. Surg. Gynecol. Obstet., 129:1213-1224.

Vracko, R., and E.P. Benditt (1970) Capillary basal lamina thickening: Its relationship to endothelial cell death and replacement. J. Cell Biol, 47:281-285.

Vracko, R., and E.P. Benditt (1972) Basal lamina: The scaffold for orderly cell replacement. J. Cell Biol., 55:406-419.

Williams, R.G. (1953) The fate of minute blood vessels in omentum transplanted as autografts to the rabbit's ear. Anat. Rec., 166:495-505.

Williams, R.G. (1959) Experiments on the growth of blood vessels in thin tissue and in small autografts. Anat. Rec., 133:465-485.

Záhoŕ, A., and C. Povýšil (1979) Cadmium necrosis in transplanted testicles as evidence for persistence of original vessels in the grafts. Am. J. Pathol., 97:223-230.

Zarem, H.A., B.W. Zweifach, and J.M. McGhee (1967) Development of microcirculation in full-thickness autogenous skin grafts in mice. Am. J. Physiol., 212: $1081-1085$. 